\title{
Automating Students' Activities in Higher Educational Institutions
}

\author{
Samuel King Opoku \\ Computer Science Department, \\ Technical University of Kumasi \\ Kumasi, Ghana
}

\author{
Samuel Appiah \\ Computer Science Department, \\ Technical University of Kumasi \\ Kumasi, Ghana
}

\begin{abstract}
The modern educational systems consist of curricular and extracurricular activities. Students are encouraged to form unions. These unions have representative roles, provide academic support and advice, offer welfare advice and support; engage in sports and social activities of which most of them are free to join. In order to make life enjoyable, students have to be better time managers. However, some of them find it difficult to prioritize their activities. This paper automates students' activities in higher educational institutions. It determines the preference of students' activities in higher educational institutions and then prioritizes them with the help of statistical tools. The associations between critical activities are determined and with the help of if-then rule set mechanism, a system that has all the users activities stored in database and alert the user the right task to perform is designed. Higher educational institutions were chosen for this study due to the dynamics of student life in these institutions
\end{abstract}

Keywords: Students; Modeling; HEI; Activity prioritization; Statistical analysis; Reasoning mechanism, Rule-based

\section{INTRODUCTION}

The ability to impart knowledge has been a major concern in human endeavor over the years. In modern educational systems, curricular and extracurricular activities form integral part of student's life. Students usually form unions. The unions are partly founded by the institution but politically independent. The unions have roles, generally some of them are; representations, academic support and advice, welfare advice and support, sports clubs, societies and social activities of which most of them are free to join. Students' unions basically believe in student being active political individuals, and campaign on various issues on national and local level [1]. Curricular activities are activities that complement academic works. Curricular activities are mandatory and they are proposed and provided by the administration of a particular institution. These activities include attending lectures, seminar presentation, submission of assignment and projects, participation in assessment examinations like midsemester exams, quizzes and end of semester exams.

Extracurricular activities are activities a student participate aside his or her academic curricular activities. Some of them include sports, student union meetings, student hall meetings, student religious denominational meetings and so forth. The extracurricular activities are beneficial to student development [2] but they should be kept at the proper place in the academic life. These extracurricular activities help them in developing various professional and leadership skills such as delegation, organization, event planning and networking. In most tertiary institutions, extracurricular activities are planned mostly by students though supervised by their heads of departments.

This paper automates students' activities in higher educational institutions. It uses statistical tools to determine the associations between critical activities which can be used to design a rule based system that has all the users activities stored in database and alert the user the right task to perform at the appropriate time. A JavaSE application is designed to implement and test the system. Higher educational institutions (HEI) were chosen for this study due to the dynamics of student life in these institutions

\section{ACTIVITY PRIORITIZATION}

Prioritization is a significant tool that helps students to focus on their tasks and duties with the highest choice. It is an effective time management method that enables one to be productive in stressful times when work is overloaded [3]. A clear understanding of time management is required for students to manage their own time effectively. In order to meet assignment deadlines and to keep up with schedules related to school and other activities, students must engage their temporal-sequential ordering abilities [4]. These skills helps interpret, retain, or create information that is in a serial order. Personal activities of students are in many forms or categories based on the priorities of a particular student. Some of the activities are performed daily, weekly, and monthly. Daily schedule helps students to plan their daily activity from the moment they wake up from bed till they go back to bed. Weekly schedule helps students to spend time as they reach a particular week. The hours or part of hours for each activity is deducted from each day's total hours. The monthly duties of tertiary students are based on study plans and their learning goals. They develop study schedule where they can block off days and times. Creating a study plan not only helps them become more organized, but it also helps them accountable for their personal learning outcomes. The students repeat this schedule plan every week till the end of every particular month.

There are many activities in tertiary institutions but difficult in fitting everyone considering their duration and time. Students check what they need to do, select and see if they can substitute with any other alternative. The process includes listing activities and dividing them into: 'Do now', 'Do soon', 'Do later' and 'Don't do'. Tertiary students undergo through steps to get their time under control. These steps include: first, listing everything they need to do. Secondly, breakdown task and lastly prioritize work list. Basic priorities provide a means for making time choices, helping to decide where it is important to invest and where not to.

On a daily basis, students also have to learn to set task priorities. Prioritizing tasks includes two steps: Determining 
what needs to be done and deciding on the order in which to do the tasks [5]. For students to be effective in their time use, they have to weed out the work that does not fit with their basic priorities [5], [6]. Deciding the order in which to do tasks means they start with the "needs" list first and then move to the "wants" list. Task prioritizing means working on the most important tasks first no matter how tempted an individual may be is to get a lot of less essential tasks out of the way [6]. A typical weekly schedule is depicted in figure 1

\section{Weekly schedule}

\begin{tabular}{|c|c|c|c|c|c|}
\hline Trme / period & Montay & Tuesday & Wodnesday & Thusaty & Fritay \\
\hline & & & & & \\
\hline & & & & & \\
\hline & & & & & \\
\hline & & & & & \\
\hline & & & & & \\
\hline & & & & & \\
\hline & & & & & \\
\hline & & & & & \\
\hline & & & & & \\
\hline & & & & & \\
\hline
\end{tabular}

Figure 1: Typical Weekly Schedule

\section{ACTIVITY MODELLING}

\subsection{Data Collection and Analysis}

To realistically determine the nature of student preferences so that it can be modelled for the design of the system, five hundred student respondents were chosen randomly from ten different HEI. Questionnaires were administered and the data was collected on nominal scale using contingency table. The data was analysed using Chi-Square test. This test though does not give much information about the strength of the relationship in the population (substantive significant) yet it can be used to determine the statistical significance of the data. With nominal data gathered, the distribution would unlikely approached normal distribution - requirement for ttext, correlation, regression, analysis of variance. Thus chisquare is the ideal test for count data. Chi-square has a major limitation. It is sensitive to sample size. The size of the calculated chi-square is directly proportional to the size of the sample. To correct this anomaly, chi-square method was complemented with measure of association, Phi coefficient $(\phi)$, which also deals with nominal data consisting of binary variables. That is a distribution with two rows and two columns. Phi coefficient eliminates sample size by dividing the chi-square by the sample size. The formula for Phi coefficient is given below in equation (1)

$$
\phi=\sqrt{ }(\text { Chi-square/sample size })
$$

When the value of $\phi$ is approximately zero, it implies, there is no correlation between the variables. When the value of $\phi$ is less than 5 , then there is a weak correlation. One the other hand, when the value of $\phi$ is great than 5 , then there is a strong correlation. Perfect correction exists when the value of $\phi$ is 1 . Positive values indicate positive correlation whiles negative values indicate negative correction. Given a contingency table with two rows and two columns, there is another way to compute the Phi coefficient without first computing the chi-square. Using the table below as an example where $\mathrm{x}$ and $\mathrm{y}$ are dichotomous variables:

Table 1. Format for Contingency Table with Dichotomous Variable

\begin{tabular}{|l|l|l|l|}
\hline $\mathrm{x} / \mathrm{y}$ & 0 & 1 & Total \\
\hline 1 & $\mathrm{a}$ & $\mathrm{b}$ & $\mathrm{a}+\mathrm{b}$ \\
\hline 0 & $\mathrm{c}$ & $\mathrm{d}$ & $\mathrm{c}+\mathrm{d}$ \\
\hline Total & $\mathrm{a}+\mathrm{c}$ & $\mathrm{b}+\mathrm{d}$ & \\
\hline
\end{tabular}

From Table 1,

$$
\phi=(\mathrm{a} * \mathrm{~d}-\mathrm{c} * \mathrm{~b}) / \sqrt{ }([\mathrm{a}+\mathrm{b}] *[\mathrm{c}+\mathrm{d}] *[\mathrm{a}+\mathrm{c}] *[\mathrm{~b}+\mathrm{d}])
$$

The above equation is used in this work. The different contingency tables were analyzed separately and independently.

The first table looked at the lectures preference of students who view religious activities superior to academic activities and vice versa. The table below summarises the outcome of data collection

Table 2. Religious and Academic Activities versus Lectures Preference

\begin{tabular}{|l|c|c|c|}
\cline { 2 - 4 } \multicolumn{1}{c|}{} & \multicolumn{4}{|c|}{ Lectures Preference } \\
\cline { 2 - 4 } \multicolumn{1}{c|}{} & Yes & No & Total \\
\hline $\begin{array}{l}\text { Religious activities supersede } \\
\text { academic activities }\end{array}$ & 95 & 175 & 270 \\
\hline $\begin{array}{l}\text { Academic activities supersede } \\
\text { religious activities }\end{array}$ & 85 & 145 & 230 \\
\hline Total & 180 & 320 & 500 \\
\hline
\end{tabular}

The Phi coefficient is calculated as:

$\phi=(95 * 145-175 * 85) / \sqrt{ }(270 * 230 * 180 * 320)$

$\phi=-0.018$

The calculation of Phi coefficient gives -0.018 which is approximately 0 , indicating that there is no correlation between religious activities or academic activities and lectures preference. Hence there is no need to model students' activities using the general religious activities and academic activities against lectures preference

The second table looked at the lectures preferences of students who view spiritual welfare superior to secular welfare and vice versa. The table below summarises the outcome of data collection 
Table 3. Spiritual and Secular Welfare versus Lectures Preference

\begin{tabular}{|l|c|c|c|}
\cline { 2 - 4 } \multicolumn{1}{c|}{} & \multicolumn{3}{c|}{ Lectures Preference } \\
\cline { 2 - 4 } \multicolumn{1}{c|}{} & Yes & No & Total \\
\hline $\begin{array}{l}\text { Spiritual welfare supersede secular } \\
\text { welfare }\end{array}$ & 285 & 19 & 304 \\
\hline $\begin{array}{l}\text { Secular welfare supersede spiritual } \\
\text { welfare }\end{array}$ & 27 & 169 & 196 \\
\hline Total & 312 & 188 & 500 \\
\hline
\end{tabular}

The Phi coefficient is calculated as:

$$
\begin{aligned}
& \phi=(285 * 169-19 * 27) / \sqrt{ }(304 * 196 * 312 * 188) \\
& \phi=0.8060
\end{aligned}
$$

The calculation of Phi coefficient gives 0.8060 which is approximately 0.8 , indicating that there is a strong correlation between individual believes and lectures preference. Thus there is the need to model students' activities taken into consideration student's believes regarding secular and spiritual welfare.

The third table looked at students skipping lectures among those who have preference of lectures to others. The table below summarises the outcome of data collection

Table 4. Lectures Preference versus skipping Lectures

\begin{tabular}{|l|c|c|c|}
\cline { 2 - 4 } \multicolumn{1}{c|}{} & \multicolumn{3}{c|}{ Skip Lectures } \\
\cline { 2 - 4 } \multicolumn{1}{c|}{} & Yes & No & Total \\
\hline Preference of lectures & 234 & 35 & 269 \\
\hline No preference of lectures & 29 & 202 & 231 \\
\hline Total & 263 & 237 & 500 \\
\hline
\end{tabular}

The Phi coefficient is calculated as:

$$
\begin{aligned}
& \phi=(234 * 202-35 * 29) / \sqrt{ }(269 * 231 * 263 * 237) \\
& \phi=0.7432
\end{aligned}
$$

The calculation of Phi coefficient gives 0.7432 which is approximately 0.7 , indicating that there is a strong correlation between individuals who have lectures preference and skipping lectures. Further examination into the reason revealed that they skip lectures for either personal or spiritual activities. Thus there is the need to model students' activities taken into consideration student's believe regarding secular and spiritual welfare

Interestingly, no one supported skipping examinations with the reason not being on medical situations. This means examinations should have highest priority on students' schedule.

\subsection{Reasoning Mechanism}

The algorithm below is used to depict the relationships of the various activities carried out by students in higher educational institution. The assumptions under which the model is defined are:
- No similar activities clash

- Each activity can be defined within specific time boundaries. Thus each activity has start time and end time.

- Scheduled extra-curricular activities do not interfere with lectures. Scheduled extra-curriculum activities refer to activities organized by the institutions such as sports, departmental or faculty week.

The user is allowed to input the various schedules at any time. The various activities are kept in a database and categorized as lectures, extra-curriculum, spiritual, examination and personal. The algorithm for its implementation is given below Begin

1. If there exist an activity called examination irrespective of any other activities then execute examination

2. If activity is extra-curriculum and no examination activity, no spiritual activities, amid lectures then suspend lectures and execute extra-curriculum activity.

3. If an extra-curriculum activity clashes with spiritual activity and no examination then

a. For each student, If spiritual welfare supersedes secular welfare then execute spiritual activity

b. Otherwise execute extra-curriculum activity

4. If extra-curriculum activity clashes with personal activity then

a. If user is a leading member of the extracurriculum activity then execute extracurriculum activity

b. Otherwise execute personal activity

5. If activity is lectures and there are no other activities then execute lectures

6. If lectures clashes with religious activity then

a. If it is public holiday then execute religious activity

b. Else, for each student, if lectures are less preferred then execute religious activity

c. Else execute lectures

7. If an activity lectures clash with personal activity and lectures are less preferred then execute personal activity. Otherwise execute lecture activities.

8. For any activity, if that activity exists solely within a particular time, then execute that activity. 
The above reasoning mechanism is implemented as flowchart in the figure below
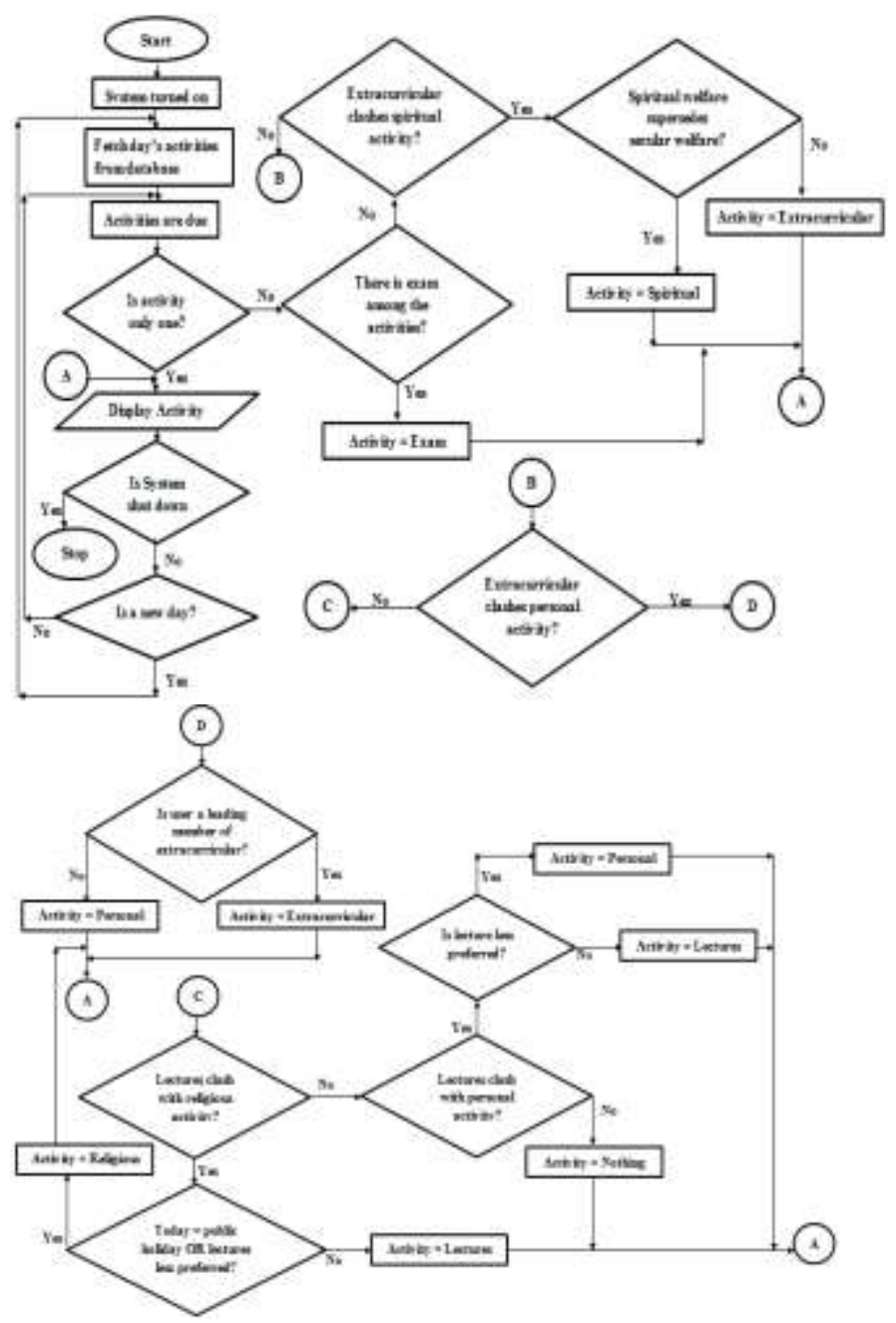

Figure 2: Flowchart for Reasoning Mechanism

\section{IMPLEMENTATION AND TESTING}

The testing system was implemented using Java Platform, Standard Edition (Java SE). This platform is rich in providing window application controls. The framework for depicting the components of the system and their interactions is shown in the figure below:

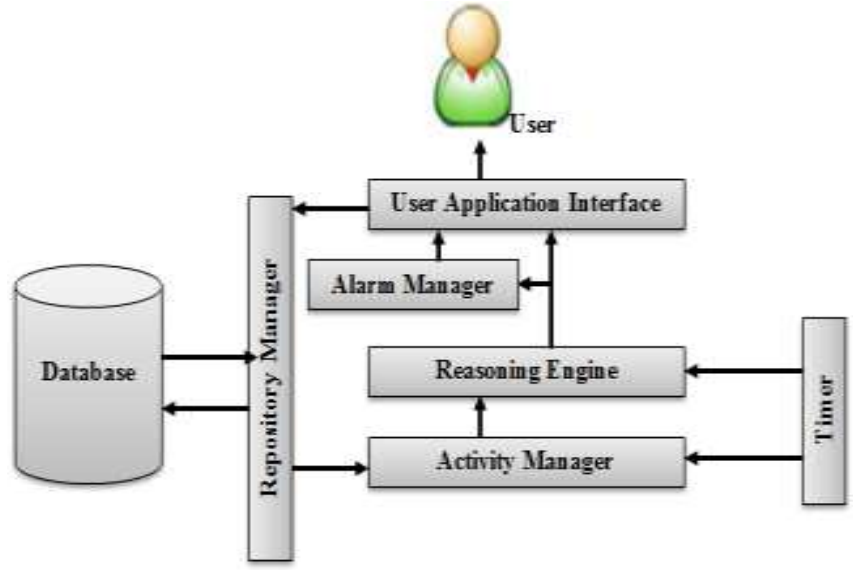

Figure 3: Interaction of System Components

The functions of the various components are:

- User Application Interface (UAI): It contains the window controls and it represents the interface between the user and the system. Users receive notifications through this component. Activities that need to be stored by the user are entered via this component. The UAI saves the users activity into a database through the Repository Manager.

- $\quad$ Reasoning Engine (RE): This component uses rules to determine which activity to display or fire taken into consideration users' preference

- $\quad$ Timer: Keeps track of the clock for each activity. It issues appropriate prompts to the Reasoning Engine and the Activity Manager helping them to trigger the appropriate actions

- Activity Manager (AM): It fetches data from the database through the Repository Manager under the influence of the Timer. Specific activities within a specific period, usually a day, are selected and kept in a dynamic array. The AM and Timer then monitors the array to determine when to fire an activity

- Repository Manager (RM): This component serves as an interface between the system and the database management system which houses the database. Two components are required to work with the database. These components are the UAI and AM UAI saves data to the database and AM fetches the data that has been saved based on the due date and time of the activities.

- The Alarm Manager (ALM): This sounds alarm when a notification is displayed

The components of the system discussed above are implements as java classes in the system. A simplified class diagram of the various components of the system is shown in the figure below: 


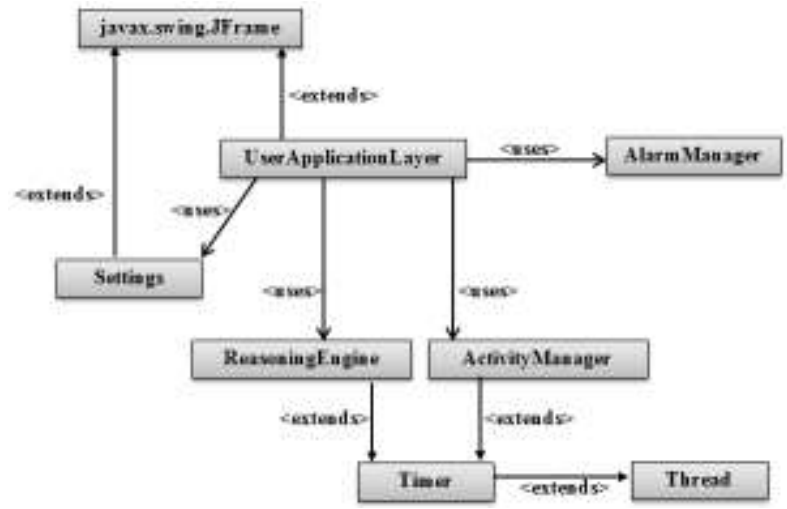

Figure 4: Class Diagram of the System Classes

In order to work with specific activities, the activities are classified and placed in a combo box for the user to select. The activities are classified as Examination, Lectures, Religious Activity, Personal Activity and Scheduled Extracurricular Activities. Activities in the database are automatically tracked. This is achieved through the threading mechanism of Java. The activities for a particular day are selected and placed in ArrayList. For every minute, the system scans through the ArrayList and check for activities that need to be fired. The system issues a reminder when there is ten minutes for an activity to be fired. A second reminder is issued when there is five minutes left for the activity to be fired. In each instance, the system sounds alarm when the notification is displayed. Figure 3 below illustrates how the notification is displayed.

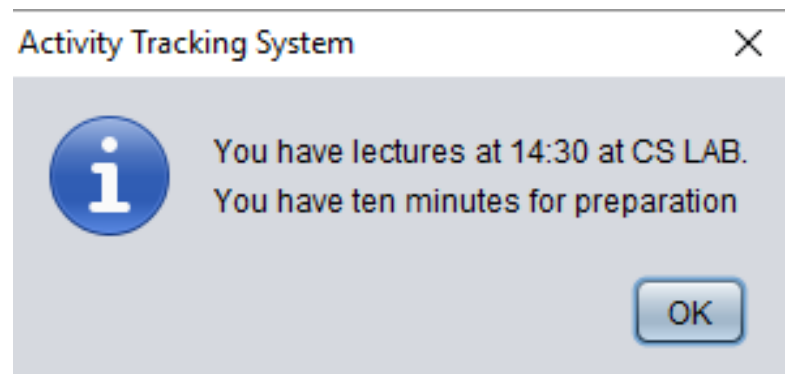

Figure 5: Activity Initialization Interface

\section{CONCLUSION}

Activities of Students in HEI have been modelled and implemented. The modelling was done with the help of statistical tools and if-then set of rules. The implementation used a high level programming language principles and ended up with a system. The system loops every minute through its database to check for activities that are due to be fired. The greatest strength of the system is that once the computer is turned on, the system starts run in the background and only fires when an activity is due. If the user wants to add or edit an activity, the user therefore explicitly open the program using the icon on the desktop. This system sets the basis for designing a context-aware reminder system through the implementation of mobile application. Future works focus on designing a mechanism to map actual activities to its categorisation. Another interesting mechanism is to design a mobile based system.

\section{REFERENCES}

[1] Jordan Dungy, Gwendolyn. "Organization and functions of student affairs." Student services: A handbook for the profession (2003): 339

[2] Marsh, Herbert W. Extracurricular activities: Beneficial extension of the traditional curriculum or subversion of academic goals? Journal of educational psychology 84.4 553,1992

[3] Claessens B. J., Van Eerde W, Rutte C. G, Roe R. A. A review of the time management literature. Personnel review. 2007 Feb 13;36(2):255-76.

[4] Johnson, James E., James F. Christie, and Francis Wardle. Play, development, and early education. Pearson/Allyn and Bacon, 2005

[5] Bozworth, C. G. MU Extension near you Challenges and Choices: Time Effectiveness-Prioritizing Your Time. Available: http://extension.missouri.edu/p/GH6653

[6] Macan, T. H., Shahani, C., Dipboye, R. L., \& Phillips, A. P. College students' time management: Correlations with academic performance and stress. Journal of educational psychology, 82(4), 760, 1990 